\title{
Social Trust and Children Born of War
}

\author{
Bogdan Voicu1 2, Ingvill C. Mochmann ${ }^{3}{ }^{*}$
}

${ }^{1}$ Romanian Academy, Research Institute for Quality of Life, 13 Calea 13 Septembrie, 050711Bucureşti, Romania

${ }^{2}$ Lucian Blaga University of Sibiu, Sociology and Social Work Unit, 2-4 Lucian Blaga, 550169 Sibiu, Romania

${ }^{3}$ Cologne Business School, 1 Hardefuststr., 50677 Cologne, Germany

${ }^{4}$ European Data Laboratory for Comparative Social Research (EUROLAB), GESIS-Leibniz Institute for the Social

Sciences, Unter Sachsenhausen 6-8, 50667 Cologne, Germany

Children born of war

Life events

Post-conflict research

Social trust

Socialization

\begin{abstract}
This paper considers two assumptions commonly used in analyzing the formation of social trust. They stress the importance of early socialization, on one hand, and of life events, on the other. We consider birth as a major life event for anyone and focus on the situation of Children Born of War. This group, even if lesser visible in some societies, has the peculiar characteristic to be born and socialized in very specific conditions. Typically, these people are the offspring of foreign soldiers, and local women. They may bear stigma, might be marginalized in family, school and society, and might develop a low level of generalized trust even if they may have lived all life in a culture rich in social trust. We explore at theoretical level their case, bring in a few statistics, and suggest a research direction that may be fruitful in learning about both such hidden populations and about social trust. In the end, we argue upon the importance of the topic for post-conflict societies.
\end{abstract}

\section{Introduction}

Two conceptual approaches dominate the literature on social trust formation (Bekkers 2012). On one hand, people tend to trust others due to specific conditions in their early childhood. The socialization assumption conceives

\footnotetext{
*Contact addresses: bogdan@iccv.ro (B.Voicu), ingvill.mochmann@gesis.org (I.C.Mochmann)
} 
trust as a moral value (Uslaner 2002), and tends to stress its stability over time. The second stream of theories imagine trust as dependent on personal experiences. It claims that positive events tends to boost trust, and to keep it at higher levels, while negative ones, including personal drama or mass traumatic episodes, may deter how much credit one gives to the other (Delhey and Newton 2003; Hardin 2006; Paxton 2007).

While many scholars consider both perspectives as valid (Bekkers 2012; Voicu 2014), this paper explores the consequences of a potential traumatic event that occurred during childhood. We focus on Children Born of War (CBOW), a particular group to be found in quite a high number of conflict and post-conflict societies, which is somehow surprisingly by contrast with their not so frequent presence on the public agenda. CBOW are fathered by foreign soldiers and local mothers, are often exposed from very birth to stigmatization, rejection and marginalization in family and society (see among other Grieg 2001; Ericsson and Simonsen 2005a; Carpenter 2007; Mochmann, Lee and Stelzl-Marx 2009).

Our paper aims to conceptualize the way in which the status of being a child born of war determines the manner in which one is more or less disposed to trust strangers. We inspect first the literature on $\mathrm{CBOW}$, to better understand their experiences, and how they grow up. Although our focus is on Europe, we try to address other parts of the world as well. Second, we review the knowledge related to social trust. We carefully consider the sources of trust and try to set up a general framework for the third section of the paper which focuses on trust and children born of war. We try to apply the theory on social trust to the concrete case of the CBOW, and to derive basic assumptions about their specific situation. Although testing is for the moment beyond our scope, we do provide indirect proof and empirical support for our claims. For this, we employ basic statistics from existing literature and the existing database. In the end, the discussion sends to potential research directions, in a field that we perceive as rich with respect to capacity to produce knowledge. 


\section{Who are the children born of war}

The Second World War in Europe is the easiest set up for explaining from where the CBOW came as research based knowledge and narratives of CBOW lives, and relations to society exists (see among others Olsen 1998; Øland 2001; Picaper and Norz 2004; Ellingsen 2004; Ericsson and Simonsen 2005b; Mochmann and Larsen 2008; Diederichs 2012). The historic facts are also well-known and provide a familiar framework, not difficult to understand. First, it was Germany displacing troops to various neighboring countries and keeping soldiers there for many years. Local women, particularly young ones, became subject of soldiers' needs and affection. Coupling occurred in various forms, from love to rape, from prostitution to platonic affection, from adultery and multiple partners to exclusive relations. Some local women simply loved the respective soldier, others did it as a compromise to survive and still others were forced to have sexual intercourse. Some of the soldiers were already married or engaged in their home country, others were simply enjoying a life that could be very short and others at least considered a postwar continuation of the relation. Considering the effects on the lives of the offspring resulting from these relations, evidence available so far indicates their experiences in post-conflict societies were quite similar (Mochmann and Larsen 2008: 352).

War was anything but a stable set up and German armies advanced further to the North, South, East and West. Then, they retreated and Russian, American, and British soldiers followed. Smaller contingents of Finns, Poles, Romanians, Hungarian, Italians, French, etc. also moved from a battlefront to another. Local women were everywhere, and many attracted the attention of the foreign soldiers. Some were received as enemies, others as liberators. Some armies were more respectful, others were simply violent and inclined to rape. Irrespectively of the situation, such relations resulted in many births. Considering only those resulting from the Third Reich expansion, reports estimate even up to 200,000 French children with German soldiers as fathers (Virgili 2005: 144), 10-12,000 children fathered in Norway by German soldiers (Olsen 1998: 48), 6-8,000 in Denmark (Øland and 
Mochmann 2011: 229), 10-15,000 in the Netherlands (Diederichs 2009: 304), some 20,000 in Belgium (Mochmann, Lee and Stelzl-Marx 2009: 267), and 100 in Greece (Muth 2008: 15). But also in other countries CBOW were born during and after WWII, for example by local women and members of the allied forces. About 23,000 children were born in Great Britain by British women and Canadian soldiers (Rains, Rains and Jarratt 2006: 16). Furthermore, an estimated 37,000 CBOW with an American soldiers as father and a German mother were born in Germany until 1946 (Lee 2009: 321) and at least 20,000 children fathered by Soviet soldiers and Austrian mothers (Stelzl-Marx 2009: 361).

Many of these children started their lives in times of trouble, and often faced the difficulty to be special compared to the other children. Their origin made them to be frequently treated as enemies. In the mind of many people in their surroundings, they were seen as a potential threat. Their fathers were soldiers, which may mean warriors, therefore the children may have inherited some of the aggressive behaviour or might even try to repeat the fathers endeavour. Such attitudes are likely to persist in societies for many years after the end of the war. Collective memory retains facts and uses them for a long time (Halbwachs 1992). A good example on how war fears persist in the collective memory can be found in Eastern European societies. Somehow frozen over the communist period, after the regime change, old tensions return as new as if the past 50 years never existed. For instance, many Easterners, but also the Western Europeans, expressed serious fears that German reunification would lead to a potential resurrection of the war (Riding 1990; Wiegrefe 2010). Such process of persistent memories of collective trauma is also likely to keep CBOW in a loop in which they had to face negative resentments for a long time. Defined as potential enemies, they grew up in at least partially unfriendly environment and faced at least from time to time suspicion of the others.

The relation between the occupation soldier and the mother of the CBOW was sometimes formally stigmatized. In France during WWII, for example, the German soldiers were warned not to interbreed with French 
women as these were not of Arian race. From the French side, the relations have been held secret as well, since they were subject to public vengeance, but also of formal punishment. The Vichy regime severely punishes adultery in order to forbid love affairs, prostitution, or other forms of relations between French women and German soldiers (Virgili 2009). Consequently, the resulting children are de facto proscribes in both societies. When pregnant, mothers have to hide, to avoid the racial laws in Germany, and the public disgrace in France. Their 'horizontal collaboration with the enemy' becomes an identity mark for their children, and remains as such for many years.

In other countries, like Belgium, special conditions made mothers of children from German soldiers to be supported by the occupiers (Lilienthal 2003). However, this was not true for all Belgian women who became pregnant with Wehrmacht soldiers. Racial laws made a clear distinction between Belgians of German or Flanders ethnicity and the Walloons. Since the latter were not Arian, as an 'inferior race', they have received no support and discrimination was obvious.

In many cases, mothers did not let the children get to know their father's identity and tabooing such facts of life was common in all occupied territories (see for example country chapters in Ericsson and Simonsen 2005a; Mochmann, Lee and Stelzl-Marx 2009). Children whose biological origin was highly visible, for example those with Afro-American fathers, faced even further complications. Most of them are to be found in the UK, were American troops stayed a long while (Lee 2009).

However, children born of war were not restricted to Europe and WWII, but are born all round the world since the Second World War. Over 1,000 kids of 'mixed blood' Koreans were born in South Korea as result of the interbreeding of American soldiers with local women in the 1950s-1960s (Grieg 2001). 20,000 is the account after Sierra Leone's ten years civil conflict in the last decade of the 20th century (Baldi and MacKenzie 2007). At least 25,000 women and girls were abducted to become wives of the rebels of the Lord's Resistance Army (LRA) in Northern Uganda's civil war which started 
in the 1980s and they are said to have gave birth to thousands of children (Apio 2007: 94-95). Undisclosed figures seem to indicate at least 'hundreds' of CBOW in East Timor, due to the Indonesian occupation in 1973-1999 (Harris Rimmer 2007).

Although we lack good estimates, many other proxies indicate potential large numbers of CBOWs in various other parts of the world. For instance, more than 200.000 women are said to have been raped during the operations of the Indian army in Bangladesh in early 1970s (Brownmiller 2013). If at least a small part gave birth, the number of resulting children is still quite large. Like in the middle age, rape continues to be an important war weapon in modern times, with local women being often considered as integral part of the spoils of war (Diken and Laustsen 2005; Gottschall 2004). In recent years, the Yugoslav segregation wars produced new $\mathrm{CBOW}$ in Europe, and many times violent relations were the source (Allen 1996; Carpenter 2010). In Kosovo, in the month of January 2010 alone, some 100 rape-babies were born (Smith 2010). They add to some other CBOW in both Bosnia (4,000; Grieg 2001) and Kosovo. The current Crimean and Ukrainian incidents, started in 2014, are likely to lead to a new group of children fathered by insurgents and local mothers to be born.

\section{The situation of children born of war}

All these new cohorts of CBOW face the same old challenges as we see from children born of WWII: stigmatization (Smith 2000); family rejection (Baldi and MacKenzie 2007); secrecy about origin (Allen 1996); being exposed to death threatens and losing the mothers (Apio 2007). Some are born while mothers are in captivity and become part of an outlaw group (Apio 2007). They frequently grow up in single-mother families (Carpenter 2010). Mothers were often subject to sexual slavery, forced marriage, or mass rape and often present signs of post-traumatic stress and disorder (Harris Rimmer 2007; Smith 2010). CBOW are exposed to various sources of material deprivation (Apio 2007). Some lack a clear identity (Apio 2007; Weitsman 
2007). Some are abandoned and grow up outside the biological family (Smith 2010). Many mix all these disadvantages together that violate basic human rights as set out in the convention on the rights of the child (Goodhart 2007; Mochmann and Lee 2010).

Table 1. Offending Names for CBOW in various countries

\begin{tabular}{|l|c|c|}
\hline Country & Label & Meaning \\
\hline Austria/Germany & Russenkind & Russian brat \\
\hline France & $\begin{array}{c}\text { Enfants de Boches } \\
\text { Fritzouilles }\end{array}$ \\
\hline Korea & \multicolumn{2}{|c|}{ Mixed-blood } \\
\hline Kosovo & Children of shame \\
\hline Norway/Denmark & Tyskerunger dishonour \\
\hline Rwanda & \multicolumn{2}{|c|}{ Devil's Children } \\
\hline Sierra Leone & Moffenkinder baby \\
\hline The Netherlands & War leftovers (for Canadian-fathered kids) \\
\hline UK & Bui doi & Children of German's whores \\
\hline Vietnam & \multicolumn{2}{|c|}{ Dust of Life } \\
\hline
\end{tabular}

Sources: see the quoted literature within the text.

Often derogatory names are given to CBOW in their respective home societies, irrespective of the époque when they are born (see Table 1). The names define them as pariah, outlaws, and mark their childhood and later life which is often characterized by social stigma and rejection. At the political level their rights are often silenced and humanitarian aid is not including them (Carpenter 2007; Carpenter 2009, 2010; Mochmann 2012; Seto 2013). This makes oppression even stronger, and social harassment becomes normality in CBOW's everyday life.

CBOW includes not solely children conceived by local mothers with enemies or allied soldiers. At least two other cases add (Grieg 2001; Mochmann 2012) children of child soldiers and children fathered by members of peacekeeping troops. However, from the point of view of the argument that we develop in this paper, their cases are similar. Our stress on the case of CBOW fathered by enemy forces, or by allied armies and local mothers was due to the simplicity of exposing the point. Otherwise, stigma, 
discrimination, taboo, harassment, suspicion, secrecy and all other phenomena also apply to all categories of CBOW. In summary, information available so far point at different dimensions which seem to be present in the different conflicts and which have an impact on the life development and life chances of children born of war. These dimensions are: the socioeconomic, the psychological, the medical/biological and the political/juridical. All these dimensions address specific factors as can be seen in Figure 1.

Figure 1. Dimensions, factors and contexts influencing the situation and life development of children born of war

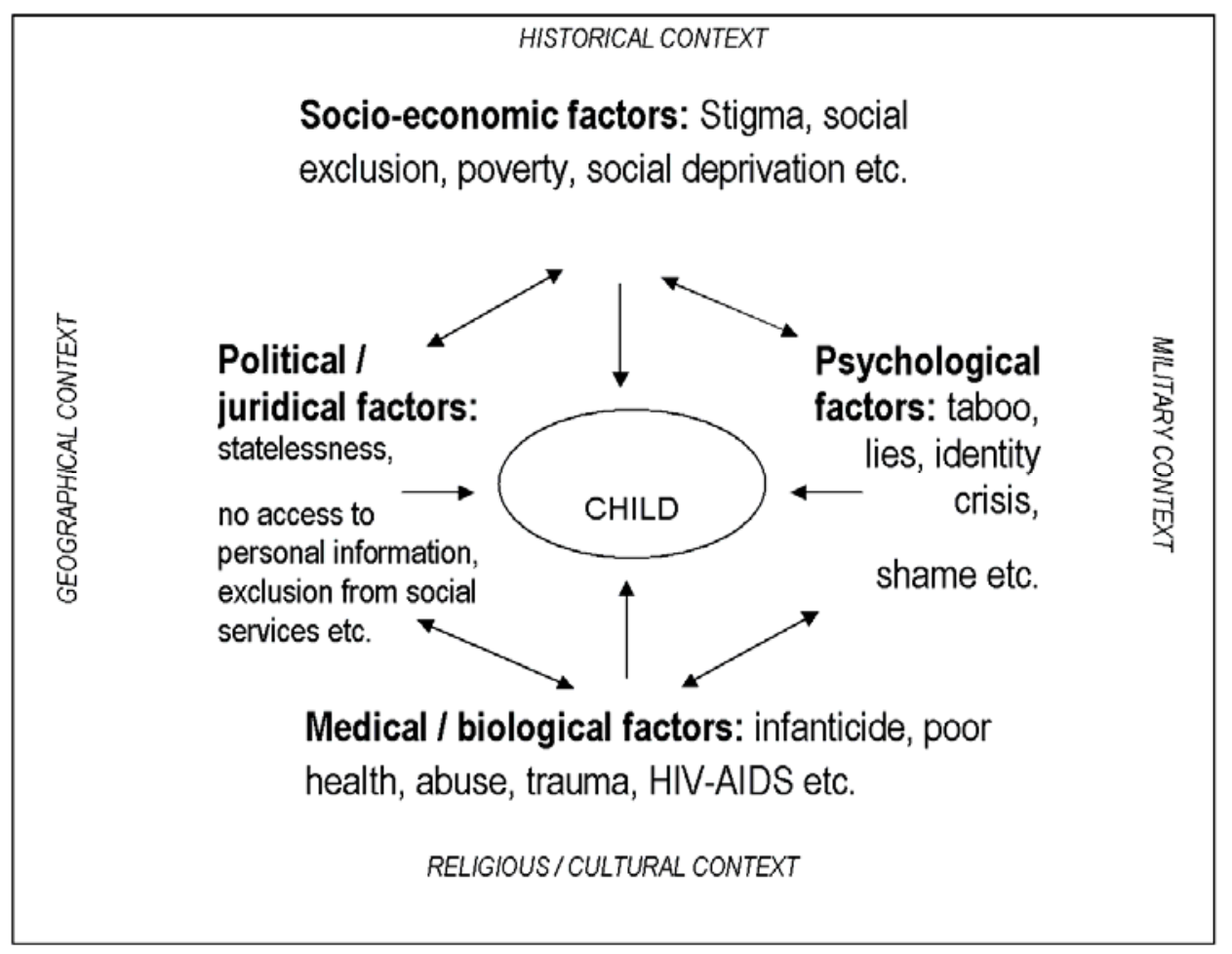

Source: Mochmann 2012: 36

Socio-economic factors include for example stigma, social exclusion, poverty, and social deprivation. The psychological dimension is 
characterized by factors such as taboo, lies, shame, and identity crises while medical/biological factors may include infanticide, poor health, abuse, trauma and HIV-Aids. Finally, the political/juridical dimension comprises factors such as statelessness, access to personal information, and access to social services (Mochmann 2012: 35-36). These factors are often interrelated in their impact on the child. An example here are the children fathered by German soldiers during the occupation of Norway during WWII. Research shows that these children had among others less education and income and poorer health compared to Norwegians from the same age cohort (Ellingsen 2004). Also, this group experience severe stigmatization and mobbing during childhood and adolescence (Ericsson and Simonsen 2005b; Mochmann and Larsen 2008). How closely these consequences for the mothers and thereby children are linked to the official policies and governmental actions in post-war Norway is very well documented in Olsen (1998), Simonsen and Ericsson (2004) and Borgersrud (2004); women who married German soldiers lost their Norwegian citizenship, were detained and deported to Germany with husband and child/children after the war and child benefit regulations were constructed in such a way that excluded the children of German soldiers from profiting only to name some of the actions taken.

In addition, different contexts are assumed to have an impact on the four dimensions and thus also on the child. These contexts are the military, the historical, the geographical and religious/ethnic and address questions such as: Is it a civil war? Are the military forces allied, enemy or peacekeeping? Is rape and torture used as military strategy? How are the countries/groups at war related historical (friends vs. enemies) and/or geographically (changing borders/sharing borders)? Is the conflict based on or influenced by religious and/ or ethnic cleavages? These contexts may not have a direct impact on the child, but are likely to have a significant impact on the four dimensions and thus indirectly on the development of the child (Mochmann 2012: 35-36). 


\section{Social trust and its sources}

People may trust specific persons or groups, but they may also direct their trust towards other people in general, towards strangers. Such generalized social trust implies a positive feeling that society as a whole and its members are trustworthy (Uslaner 2002). Generalized or social trust defines the extent to which individuals are sure that they can rely on others, that others will provide help, will not develop negative attitudes and actions if not harmed, will not set as purpose to produce damages on properties, threaten life, or hinder harmless actions and the fulfilment of needs (Hardin 2006).

Trust acts as a way to control and predict environment (Luhmann 1979), or actually to increase the feeling that environment is safe. Trusting others means that one is sure that those around will behave according to the rules. Let suppose that two individuals, $\mathrm{A}$ and $\mathrm{B}$, interact. A and B are complete strangers to each other. As trustful person, A will not waste time and energy trying to find out if $\mathrm{B}$ will observe the rules, and will act according to the social convenience. A will therefore engage in the contact with the complete stranger B without hesitation, simply on the ground that A has a high level of social trust. If A and B have lower social trust, a long stage of mutual exploration, which might look like a blind groping, would precede the moment when they actually start to cooperate. Social trust guarantees therefore more certainty in respect to the social environment. This becomes predictable, and people who trust others reduce interaction and transaction costs.

But trusting others is not simple. A view from the rational theory (Hardin 2006: 19-20) says that one should trust others if one is convinced that others will act in such a way that his/her interests will be promoted. Weighting costs and risks induced by the act of trusting against the potential benefits to be derived leads to trust, but this depends on non-rational factors (Frederiksen 2012), such as how probable the risks are to occur. Therefore, the act of trusting is not necessary related to the Trustee's person, but to how much the Trusting Person believes that the own interests 'are encapsulated in the interests of the Trustee'. In other words, a strong conviction that when 
the Trustee person follows own's interests the interests of the Trusting one are encapsulated as well may be a rational explanation for the formation of trust. However, this entire process implies a strong confidence that moral norms will be respected, and people do not harm each other, or at least they do not do it on purpose. Such conviction should also rely on own trustworthiness, under the presumption that others will behave similarly. This was actually shown experimentally (Ermisch et al. 2009): people who trust others tend to be trustworthy and the opposite.

The sources of trust may lie in psychological predisposition to trust (Glanville and Paxton 2007) and personality traits, such as optimism (Delhey and Newton 2003), or can be learned from society. One can learn to trust from parents during early childhood, within the primary socialization. Various life experiences and the exposure to societal norms can be another source for the social learning model. Outside the psychological explanations, learning trust in early childhood or due to experiences during adulthood are the two main approaches to trust formation and change (Bekkers 2012; Dinesen 2013; Stolle and Hooghe 2004). On one hand, relating trust to social norms, it becomes a moral value (Uslaner 2002). The widespread opinion about values is that they are stable over lifetime (Hitlin and Piliavin 2004; Jagodzinski 2004), therefore social trust may be stable as well. In fact, it has been shown that its stability can be compared with the one of the five big personality traits (Bekkers 2012). Even more, compelling evidences seem to indicate that the trust culture in the grandparents' country of origin of tend to leave a strong imprint on the social trust of their grandchildren (Uslaner 2008).

However, reliable testing shows that the social learning model is more effective in explaining trust (Glanville and Paxton 2007). In other words, despite its stability, social trust is subject to permanent change, due to learning from the context. On one hand, there is the inherent value change, as current literature in the sociology of values claims (Arts 2011; Beck and Beck-Gernsheim 2001; Gundelach 1994). People are exposed to various contexts and tend to adopt social norms, repeat them as behaviours and 
internalize them until they become part of their system of values. Social change may be the source (Voicu and Bartolomé-Peral 2011), but such cases of fast societal change are unlikely to occur frequently. Contagion with other cultures is another, more likely, salient factor in this regard, and has been empirically tested for the case of international immigrants (Dinesen and Hooghe 2010; Voicu 2014). While keeping the culture of social trust from their country of origin, immigrants tend also to adopt the typical level of trust of the host society and to mix the two. From our point of view, the important lesson is that trust changes during adulthood and even at older ages. As manifestation of social capital, trust is embedded in cultures of trust, persistent either at country- or regional- level (Bădescu and Sum 2005; Fukuyama 1995; Pichler and Wallace 2007; Putman 1993). Strong social norms of trust tend to model how people behave and how much they trust others to encapsulate their own interests.

It is not only the culture of trust that matters, but also other contextual variables such as living in a no fault divorce culture (where lower certainty about marriage stability makes women to trust less - Viitanen 2014), protestant ethic (Bjørnskov 2006), gender equality in labor force participation (Mewes 2014), etc.

The second type of change due to late socialization is the one dependent on personal or mass-experiences. On one hand, repeated positive outcomes resulting from contact with other individuals, particularly if these are previously unknown, may lead to increasing levels of social trust (Delhey and Newton 2003; Hardin 2006; Paxton 2007). Daily interaction is likely to provide individuals with more knowledge about the others, makes them better understand their ways, and is likely to foster social trust (Voicu 2010). While this is a debatable hypothesis with respect to involvement in associations (Bekkers 2011; Sønderskov 2011), there is empirical evidence that it holds true with respect to informal interactions (Delhey and Newton 2003; Glanville, Andersson and Paxton 2013).

On the other hand, negative experiences have the opposite effect. They might be of personal nature, such as divorce (Lindström 2012; Paxton 2007) 
or parental divorce (King 2002), or might be related to exposure to masstraumatic events, such as natural disasters (Dang 2012).

Due to the focus of this paper, traumatic events deserve a particular attention. They are not particularly present in the literature devoted to social trust. At general level, stressful events are studied rather in psychology. However, since such experiences tend to produce negative effects in the life of any individual, they are relevant for social sciences as well. Cognitive reworking theory puts negative life events in the framework of the need to find personal balance and meaning of everyday life. Each daily life fact is reinterpreted and used to derive lessons for the future. However, when dealing with more recent or even more distant traumatic events, one faces difficulties to find positive meanings in such experience (Tait and Silver 1989). Immediate life changes derive from extremely stressful events, and they may affect the daily routines, may disrupt the personal networks, may lead to loneliness, may involve depression and social marginalization. In some cases the world becomes strange and unpredictable, people seem not able to understand their own feelings and apparently lack empathy. Low trustworthiness is likely to be the outcome. People tend to rework their coping strategies depending on their life experiences, or rather depending on their representations about their experiences and about the world, as the assumptive world theory states (Janoff-Bulman 1992). Traumatic or stressful events deeply shatter the conviction that world is a good place to be, that people are helpful, and life is fair. These are exactly those assumptions that are at the very basis of social trust, exactly those beliefs about predictability of the social environment. Negative trust, if one can use the concept in this manner, should be the consequence of traumatic events.

Exposure to discrimination and perceiving tensions within the society can be treated as two other types of negative life-experiences. If one is facing constant threats or perceives the society as instable, this immediately questions the mere conditions that lead to trust formation and its maintenance. Constant threats and being discriminated hinder the basic feeling that own interests are encapsulated in the interests of others. 
Consequently, trust loses its rational grounds. Empirical proof shows that there is higher trust among those who say that there are only few conflicts within society (Delhey and Newton 2003). In addition, those who experience continuous discrimination are less likely to develop trust (Heim, Hunter and Jones 2011; Nunnaly 2012; Rothstein and Stolle 2003).

\section{Children born of war and social trust}

Children experiencing war feel traumatic effects for the rest of their lives (Dyregrov, Gjestad and Raundalen 2002; Leavitt and Fox 2014). Children born of war also reflect their situation at least many years into their adulthood. However, they might be in an even more difficult situation. As we have shown, they have to add their personal trauma to the collective one. They experience tabooing their origin, secrecy around their biological father, they often grow up in single-mother families, are exposed to public stigmatization, marginalization, and during childhood they are portrayed as potential enemies. When exposed to war, children grow up in an atmosphere of hatred and conflictual ideology (Barenbaum, Ruchkin and Schwab-Stone 2004: 46-47). For CBOW, this generalized mistrust outside the immediate ethnic group is in fact directed towards themselves. They are not only different, but they are that type of different individuals that caused trouble to the others. There is a lot of mistrust that they have to face, and, based on mutuality, to reflect it and eventually internalize it as personal value. Such daily stressor might be also an important moderator even for impact of witnessing war violence on mental health (Miller and Rassmusen 2010).

Children exposed to war and to post-war periods learn to celebrate war heroes and internalize their battle as a legitimate one (Barenbaum, Ruchkin and Schwab-Stone 2004). For CBOW of fathers from eventually defeated occupation forces, this might be even more disrupting. They actually celebrate the fighting of those who fought against and ultimately crushed the army of their own fathers. This is not an easy fact to swallow. 
An assumption is that this can challenge the mere grounds of personal selfconfidence, and due to this might affect the way in which a CBOW interrelates with others. Trust might be seen as the core element in the process, and it is more likely to turn into mistrust. Caution should govern the life of an excluded member of the society, who misses the protective coverlet of the social understanding, and is frequently exposed to unfriendly behaviours and attitudes. General lack of confidence is likely to be gradually internalized.

Children experiencing violent war events are likely to develop posttraumatic stress disorder, but, on the other hand, they are also likely to manifest pro-social behaviours (Macksoud and Aber 1996). CBOW are less likely to have witnessed such events, and to see their friends exposed to enemy's repression, but are, as has been pointed out previously, often exposed to prejudice and stigma of their peers and of their own community. Tabooing, permanent discrimination, and marginalization are therefore the first part of the story. Their pervasive effects might make social trust to become an almost prohibited dream. Many CBOW face from the very beginning of their life a lot of adverse conditions and societal rejection. They need to cut their life not only through a hostile society, but sometimes even through familial suspicions and accuses. This creates a highly uncertain environment, which have little chances to boost trust. Mistrust is the more plausible outcome. According to the early socialization assumption, this should be pervasive over the entire adulthood. The fear to disclose real identity, and sometimes the difficulties to accept it as such, may deter the self-confidence. Loneliness and reduced capacity to socialize tend to follow. Lower number and frequency of informal interactions may add to the factors that harm creation of trust during adolescence and young adulthood (Rotenberg et al. 2010).

A further cultural effect comes from the mere fact that the whole society traversed a war, and resents its traumatic effects. Daily stressors are present for all individuals, at least for a while, and tend to hinder the creation of social trust. Suspicion is directed not only to CBOW, but also to 
all social groups different than the own. A whole package of mistrust or lower trust than expected is present, and acts as general framework to guide individual attitudes and behaviours. This is important if considering those views that define trust (and social capital) as a cultural trait. Due to war experiences, many of them traumatic, all society tends to be rather cautious than trustful. A culture of mistrust is probably dominant in early childhood, and it takes time until people will start to have fewer fears about the way in which others might act. In the light of the cultural determinacy, the CBOW will tend to have low trust anyway, while their particular situation will deter even further how much they will rely on others as trustful.

\section{Empirical evidence on CBOW and social trust}

The literature devoted to children born of war paid little attention up to now to their level of social trust. It describes all the preconditions that we have identified in the previous section, but it almost never directly addresses what happens with CBOW's attitudes towards people in general, towards how much cautious one should be in social relations or to which extent people should expect others to be helpful.

The theme is at most marginal, but it is still documented by same empirical proof. It appears as a specific distrust resented by a Filipino Amerasian CBOW-women towards men, resulting from how family structures in early childhood have been like (Grieg 2001: 90-91). It comes back as lack of self-confidence of a Dutch mother, having a CBOW of her own, fathered by a German soldier during the Second World War (Diederichs 2009: 308-309). Interviewed in mid-1990s, she still recalls old fears and lacks trust to openly speak about her love relation, and simply declares that she lacks trust even in herself to do so. A similar input describing lack of self-confidence comes from the more recent Rwandan example (Mukangendo 2007: 44).

Some more comprehensive data was collected and prepared by an international research group working on the project 'A comparative study 
on Danish, Norwegian and Dutch war children'1 (Diedrichs 2012; Mochmann and Larsen 2008, see Table 2; Mochmann and Øland 2009). The survey was carried out among 650 members of the Norwegian War Child Association (NKBF) in 1997 and with almost 400 members of the Danish War Child Association (DKBF) in 2003. In addition, there were about 50 responses in the Netherlands. The survey was carried out through written questionnaires that included both standardized and open-ended questions. Altogether, the survey includes 250 questions about the respondent's childhood, youth, parents, identity, school years, health, experiences, and other topics. It should be emphasized that the sample is not representative for all $\mathrm{CBOW}$ as the respondents are mainly members of the associations. Furthermore, the proportion of women is larger than men in all three countries. The main goal of this survey was to learn more about the childhood experiences of CBOW fathered by German soldiers in different European countries during WWII.

One should pay attention that such data are not exact measures of social trust, but rather proxies related to the consequences of lacking trust and determinants of low confidence. With such caution in mind, one may see that CBOW in Norway and Denmark report with a certain frequency to have problems in interaction with others which might be partially due to lacking trust. Sadness and depression tend to be quite common, particularly in Norway, but also among Danish women. There are likely to deter trust, and engaging in informal interactions (which would boost trust). However, one should keep in mind that such results should be contrasted to what happens in the entire population. On the other hand, the Norwegian and Danish CBOW are born during and immediately after the Second World War, and were interviewed in the 2000s, that is when they are in their 60s. Time might be an important variable here, and more other influences might be blended in their current levels of social trust, or in the three indicators

\footnotetext{
${ }^{1}$ The principal investigator is Prof. Stein Ugelvik Larsen, Department of Comparative Politics, University of Bergen, Norway. Members of the group are Stein Ugelvik Larsen and Elna Johnsen, Norway, Arne Øland, Denmark, Ingvill C. Mochmann, Germany, and Monika Diedrichs, the Netherlands.
} 
included in Table 2.

Table 2. Negative feelings in CBOW in Norway and Denmark

\begin{tabular}{|l|c|c|c|c|}
\hline & \multicolumn{2}{|c|}{ Norway } & \multicolumn{2}{c|}{ Denmark } \\
\hline & men & women & men & women \\
\hline Problems in contact with other people & $26 \%$ & $27 \%$ & $18 \%$ & $24 \%$ \\
\hline Sadness or depression & $46 \%$ & $56 \%$ & $22 \%$ & $44 \%$ \\
\hline Anxiety & $31 \%$ & $42 \%$ & $13 \%$ & $29 \%$ \\
\hline
\end{tabular}

Source: Excerpt from Mochmann and Larsen (2008: Table 2). The exact wording of the question was 'Have you during adolescence and until today experienced any of the following problems?' The figures in the table are percentages from multiple answers.

At present research projects on psycho-social consequences, stigmatization and identity development among children born of war fathered by allied forces in Germany and Austria and German soldiers in Norway during WWII are being carried out. This survey consists of three research projects which apply almost identical questionnaires and whose members closely cooperate: 'Psychosoziales Befinden, Erfahrungen mit Vorurteilen und Identitätsentwicklung von Besatzungskindern in Deutschland'; 'Psychosoziales Befinden, Erfahrungen mit Vorurteilen und Identitätsentwicklung von Besatzungskindern in Österreich' and 'Krigsbarn i Norge - psykosomatiske konsekvenser, identitetsutvikling og erfaringer med fordommer - en spørreundersøkelse blant norske krigsbarn'2. In addition to $\mathrm{CBOW}$ specific questions adopted from the above cited survey by Larsen et al. this questionnaire includes several established scales measuring amongst others aversive childhood experiences, trauma, and stigmatization (Glaesmer et al. 2012). In particular, the surveys include the Adult Attachment Scale which measures emotions, experiences and behaviour when in contact with other people and which could thus be used to compute a factor of generalized trust. The results may be compared across the different groups of CBOWs in the respective countries and may thus provide us with valuable insights on if, how and why trust of children born of war

2 Principal investigators are, in alphabetic order, Heide Glaesmer, Marie Kaiser, Philipp Kuwert, Martin Miertsch, Ingvill C. Mochmann, Ketil J. Ødegaard and Barbara Stelzl-Marx. 
varies across biological background and country.

\section{Consequences for future research directions}

Trust is one of the important topics in the social sciences of the New Millennium. Promoted as top issue during (but also before) the debate around social capital, it remained on the top of the public agenda for decades. Its interbreeding with solidarity and social cohesion was important; the same is valid for the approaches defining trust as prerequisite for democracy (see Sztompka 1998, 1999). From this point of view, post-conflict areas may be seen as social frameworks in which building trust is a 'must $\mathrm{do}^{\prime}$. As we argued, CBOW are part of the post-conflict picture, and their ability to integrate might be an indicator for the society's capacity to take care of its citizens. Low trust leads to loneliness, particularly during childhood, adolescence and early adulthood. This manifests as a situation in which the quality and the number of relevant relationships is reduced (de Jong Gierveld, Van Tilburg, and Dykstra 2006). Lack of relationships implicitly decreases civic participation. If a whole group develops such syndromes, a fragmented society is the potential outcome.

Post-conflict researchers, interested in re-starting the engine of development, should be interested in the topic. Our paper simply intends to open the way for these research directions. We have used conceptual approaches based on empirical evidence that we have depicted from two different sources: the literature on social trust, on one hand, and the one on children born of war, on the other. Marginally we have also addressed approaches related to experiencing traumatic life events, and to the consequences of war, particularly on children. From here, we have derived a framework that describes the conditions in which and the mechanisms through which CBOW would end up with lower levels of social trust, and such situation would become pervasive over the life course. Very little empirical proof is to be found in existing published literature. However, newer data seems to allow further testing and theoretical development. We 
indicated how using data from ongoing research projects may find out to which extent our conceptual developments hold true. The data sets include enough information to control for various conditions during early childhood and in adult life, and may in some of the countries be compared to results from population based surveys which may analyses of the actual processes that lead to lower trust which may prevent mistrust. Family support, a tolerant community, informed schooling practices might be part of the cure.

Other battle zones in Europe were almost ignored up to now. The cold war has frozen the debate over Eastern Europe. During the $2^{\text {nd }}$ World War, countries like Poland, Hungary and Romania, experienced the presence of both German and Soviet troops. Irrespectively if labelled as allies, invaders, or liberators, both Germans and Soviets interacted with the local population, including local women. Taking Romania as example one may remember its alliance with Germany starting 1941. German soldiers were camped, for instance, around Ploieşti and in the entire Valea Prahovei, to protect what used to be at that age the main European oil reservoir. Americans were raiding the area in their main European battlefield of the $2^{\text {nd }} \mathrm{WW}$ (Stout 2003). When the Romanians switched arms, Soviet soldiers replaced the Germans and remained there as occupation forces until 1958, with a peak of some 600,000 Soviet soldiers to be found in the country in 1946. Due to the cold war and communist censorship, testimonials of resulting children are rare, but they started to be present after 1990. Media reports stress the rape events (e.g. Burlă and Stoica 2014), but they also tell stories about CBOW (Popescu 2014). The authors of this paper have got in touch with anecdotic stories about CBOW, which seem to point to differences between the destiny of those fathered by Russian soldiers and those fathered by German soldiers. A study of the Eastern-European CBOW resulting from the ${ }^{\text {nd }}$ World War might further refine the knowledge in the field, and should be a research direction to be developed in the near future. Carefully depicting the coping mechanisms used in this area will allow a more accurate drawing of policies to be implemented in post-conflict zones.

However, this would be restricted to a certain cultural framework. 
Comparisons to other former battlefields should be pursued. Scholars have the opportunity to consider conflicts that are more recent. They may include, for instance, Afghanistan, Bosnia, Kosovo, Rwanda, Mali, NagornoKarabakh, etc. This would move the debate in a comparative perspective, allowing disentangling universal social laws from specific ones. Panel studies might be designed to follow $\mathrm{CBOW}$ and their cogeneration peers over long periods (cf. Mochmann 2012).

Beyond the benefit for post-conflict reconstruction, such approach is also important for the debate around social trust per se. It would allow to assess the impact of atypical birth conditions, and of constant discrimination from own peers. By doing so, one could better inform the debate related to social trust formation, and help finding an explanation to conciliate the socialization and institutionalization hypotheses.

Finally, the obvious outcome is a better understanding of the life and needs of the mere group of CBOW. While with respect to post-conflict reconstruction and theories of social trust formation, the case of $\mathrm{CBOW}$ plays the role of an unpleasant natural experiment, the findings of our theoretical considerations in this paper, to be further tested by empirical analysis, refer mainly to the situation of this disadvantaged group. We expect that children born of war are likely to develop lower social trust due to their specific condition. This needs proper addressing from very early childhood and along the life course, in order to enable them to better integrate into society and to have a harmonious personal development.

\section{Acknowledgements}

The authors are grateful to Andrea Meckel for a careful reading of the text and useful comments and sugestions.

\section{References}

Allen, Beverly. 1996. Rape warfare: The hidden genocide in Bosnia-Herzegovina and Croatia. Minneapolis: University of Minnesota Press.

Apio, Eunice. 2007. “Uganda's Forgotten Children of War." In Born of War. 
Protecting Children of Sexual Violence Survivors in Conflict Zones, edited by R. Charlie Carpenter, 94-109. Bloomfield: Kumarian Press.

Arts, Will. 2011. "Explaining European Value Patterns: Problems and Solutions." Studia UBB Sociologia LVI (1): 7-31.

Bădescu, Gabriel and Paul E. Sum. 2005. "Historical Legacies, Social Capital and Civil Society: Comparing Romania on a Regional Level." EuropeAsia Studies 57(1): 117-133.

Baldi, Giulia and Megan MacKenzie. 2007. "Silent Identities. Children Born of War in Sierra Leone." In Born of War. Protecting Children of Sexual Violence Survivors in Conflict Zones, edited by R. Charlie Carpenter, 78-93. Bloomfield: Kumarian Press.

Barenbaum, Joshua, Vladislav Ruchkin, and Mary Schwab-Stone. 2004. "The psychosocial aspects of children exposed to war: practice and policy initiatives." Journal of Child Psychology and Psychiatry 45(1): 41-62.

Beck, Ulrich and Elisabeth Beck-Gernsheim. 2001. Individualization. Institutionalized Individualism and Its Social and Political Consequences. London: Sage.

Beevor, Antony. 2007. Berlin: the downfall 1945. London: Penguin.

Bekkers, Ruud. 2012. "Trust and Volunteering: Selection or Causation? Evidence from a 4 Year Panel Study." Political Behavior 34(2): 225-247.

Bjørnskov, Christian. 2006. "Determinants of generalized trust: A crosscountry comparison." Public Choice 130(1): 1-21.

Borgersrud, Lars. 2004. Staten og krigsbarna: En historisk undersøkelse av statsmyndighetenes behandling av krigsbarna $i$ de første etterkrigsårene. Oslo: Institutt for kulturstudier, Universitetet i Oslo.

Brownmiller, Susan. 2013 [1975]. Against our will: Men, women and rape. Open Road Media.

Burlă, Virgil and Ionel Stoica. 2012. “Exclusiv EVZ. Fărădelegile şi crimele oribile comise de Armata Roşie în România după 23 august 1944. Soldații sovietici au PRĂDAT ca barbarii." Evenimentul Zilei, June 26. Available at http://www.evz.ro/davai-ceas-nu-este-mit-faradelegile -armatei-rosii-fata-de-romani-dupa-23-august-1944.html (accessed August 24, 2014).

Carpenter, Charli. 2010. Forgetting children born of war: setting the human rights agenda in Bosnia and beyond. New York: Columbia University Press.

Carpenter, R. Charli (ed.) 2007. Born of War. Protecting Children of Sexual Violence Survivors in Conflict Zones. Bloomfield: Kumarian Press.

Carpenter, R. Charli. 2009. “Orphaned Again? Children Born of Wartime Rape as a Non-Issue for the Human Rights Movement." In The International Struggle for New Human Rights, edited by Clifford Bob, 
14-29. Philadelphia: University of Pennsylvania Press.

Dang, AD. 2012. "Cooperation makes beliefs: Weather variation and sources of social trust in Vietnam." ANU Working Paper Series in Economics and Econometrics 596, http://cbe.anu.edu.au/media/2405932/ wp596 .pdf.

Delhey, Jan and Ken Newton. 2003. "Who trusts? The origins of social trust in seven nations." European Societies 5(2): 93-137.

Diederichs, Monika. 2009. "〈Moffenkinder»: Kinder der Besatzung in den Niederlanden." Historical Social Research/Historische Sozialforschung 33(1): 304-320.

Diedrichs, Monika. 2012. Kindern van Duitse militairen in Nederland. En verborgen leven. Soesterberg: Aspekt.

Diken, Bülent and Carsten Bagge Laustsen. 2005. “Becoming Abject: Rape as a Weapon of War." Body and Society 11(1): 111-128.

Dinesen, Peter Thisted and Marc Hooghe. 2010. "When in Rome, Do as the Romans Do: The Acculturation of Generalized Trust among Immigrants in Western Europe." International Migration Review 44(3): 697-727.

Dinesen, Peter Thisted. 2013. “Where You Come From or Where You Live? Examining the Cultural and Institutional Explanation of Generalized Trust Using Migration as a Natural Experiment." European Sociological Review 29(1):114-128.

Drolshagen, Ebba D. 2005. Wehrmachtskinder. Auf der Suche nach dem nie gekannten Vater. München: Knaur.

Dyregrov, Atle, Rolf Gjestad, and Magne Raundalen. 2002. "Children exposed to warfare: A longitudinal study." Journal of Traumatic Stress 15(1): 59-68.

Ellingsen, Dag. 2004. En registerbasert undersøkelse. Statistics Norway, Rapport Nr. 2004/19.

Ericsson, Kjersti and Eva Simonsen (eds.). 2005a. Children of World War II. The hidden enemy legacy. Oxford/New York: Berg.

Ericsson, Kjersti and Eva Simonsen. 2005b. Krigsbarn I Fredstid. Oslo: Universitetsforlaget.

Ermisch, John, Diego Gambetta, Heather Laurie, Thomas Siedler, and S.C. Noah Uhrig. 2009. "Measuring people's trust." Journal of the Royal Statistical Society 172(4): 749-769.

Frederiksen, Morten. 2012. “Dimensions of Trust: An Empirical Revisit to Simmel's Formal Sociology of Intersubjective Trust." Current Sociology 60(6): 733-750.

Fukuyama, Francis. 1995. Trust: The Social Virtues and the Creation of 
Prosperity. New York: Free Press.

Glaesmer H, Marie Kaiser, Harald J. Freyberger, Elmar Brähler, and Philipp Kuwert. 2012. “Die Kinder des Zweiten Weltkrieges in Deutschland Ein Rahmenmodell für die psychosoziale Forschung." Trauma and Gewalt - Forschung und Praxisfelder 6(4): 319-328.

Glanville, Jennifer L. and Pamela Paxton. 2007. “How Do We Learn to Trust? A Confirmatory Tetrad Analysis of the Sources of Generalized Trust." Social Psychology Quarterly 70(3): 230-242.

Glanville, Jennifer L., Matthew A. Andersson,and Pamela Paxton. 2013. “Do Social Connections Create Trust? An Examination Using New Longitudinal Data." Social Forces 92(2): 545-562.

Goodhart, Michael. 2007. "Children Born of War and Human Rights. Philosophical Reflections." In Born of War. Protecting Children of Sexual Violence Survivors in Conflict Zones, edited by R. Charli Carpenter: 188-209. Bloomfield: Kumarian Press.

Gottschall, Jonathan. 2004. "Explaining wartime rape." Journal of Sex Research 41(2): 129-136.

Grieg, Kai. 2001. "The War Children of the World". War and Children Identity Project (WCIP), Bergen.

Gundelach, Peter. 1994. "National Value Differences: Modernization or Institutionalization?" International Journal of Comparative Sociology 35(1): 37-58.

Halbwachs, Maurice. 1992. On collective memory. Chicago: University of Chicago Press.

Hardin, Russell. 2006. Trust. Malden: Polity Press.

Harris Rimmer, Susan. 2007. "Orphans or Veterans? Justice for Children Born of War in East Timor." In Born of War. Protecting Children of Sexual Violence Survivors in Conflict Zones, edited by R. Charlie Carpenter, 53-77. Bloomfield. Kumarian Press.

Heim, Derek, Simon C. Hunter and Russell Jones. 2011. "Perceived Discrimination, Identification, Social Capital, and Well-Being: Relationships with Physical Health and Psychological Distress in a U.K. Minority Ethnic Community Sample." Journal of Cross-Cultural Psychology 42(7): 1145-1164.

Hitlin, Steven and Jane Allyn Piliavin. 2004. "Values: Reviving a Dormant Concept." Annual Review of Sociology 30: 359-393.

Jagodzinski, Wolfgang. 2004. "Methodological problems of value research." In Comparing Cultures: Dimensions of Culture in a Comparative Perspective, edited by Henk Vinken, J. M. M. L. Soeters and Peter Ester, 97-121. Leiden: Brill. 
Janoff-Bulman, Ronnie. 1992. Shattered assumptions: Towards a new psychology of trauma. New York: Free Press.

Jong Gierveld, Jenny de, Theo Van Tilburg, and Pearl A. Dykstra. 2006. Loneliness and social isolation. In Cambridge handbook of personal relationships, edited by Anita L. Vangelisti and Daniel Perlman, 485500. Cambridge: Cambridge University Press

King, Valarie. 2002. "Parental divorce and interpersonal trust in adult offspring." Journal of Marriage and Family 64(3): 642-656.

Leavitt, Lewis A. and Nathan A. Fox (eds). 2014. The psychological effects of war and violence on children. Psychology Press.

Lee, Sabine. 2009. "Kinder amerikanischer Soldaten in Europa: ein Vergleich der Situation britischer und deutscher Kinder." Historical Social Research 34(3): 321-351.

Lilienthal, Georg. 2003. Der "Lebensborn e.V.". Ein Instrument nationalisozialistischer Rassenpolitik. Frankfurt: Fischer.

Lindström, Martin. 2012. "Marital status and generalized trust in other people: A population-based study." The Social Science Journal 49(1): 20-23.

Luhmann, Nicklas, 1979. Trust, and power. Chichester: Wiley.

Macksoud, Mona S. and J. Lawrence Aber. 1996. “The war experiences and psychosocial development of children in Lebanon." Child development 67(1): 70-88.

Mewes, Jan. 2014. "Gen(d)eralized Trust: Women, Work, and Trust in Strangers." European Sociological Review 30(3): 373-386.

Miller, Kenneth E. and Andrew Rasmussen. 2010. "War exposure, daily stressors, and mental health in conflict and post-conflict settings: bridging the divide between trauma-focused and psychosocial frameworks." Social Science and Medicine 70(1): 7-16.

Mochmann, Ingvill C. 2012. "Children Born of War - Individual Destinies between Societal and International Responsibilities." Replikk 33: 3239.

Mochmann, Ingvill C. and Arne Øland. 2009. “Der lange Schatten des Zweiten Weltkriegs: Kinder deutscher Wehrmachtsoldaten und einheimischer Frauen in Dänemark." Historical Social Research 34(3): 282-303.

Mochmann, Ingvill C. and Sabine Lee. 2010. "The Human Rights of Children Born of War: Case Analyses of Past and Present Conflicts." Historische Sozialforschung 35(3): 268-298.

Mochmann, Ingvill C. and Stein Ugelvik Larsen. 2008. "The forgotten consequences of war: The life course of children fathered by German 
soldiers in Norway and Denmark during WWII - some empirical results." Historical Social Research 33 (1): 347-363.

Mochmann, Ingvill C., Sabine Lee, and Barbara Stelzl-Marx. 2009. "The Children of Occupation Born During the Second World War and Beyond - An Overview." Historical Social Research 34(3): 263-282.

Mukangendo, Marie-Consolée. 2007. "Caring From Children Born of Rape in Rwanda." In Born of War. Protecting Children of Sexual Violence Survivors in Conflict Zones, edited by R. Charlie Carpenter, 40-53, Bloomfield. Kumarian Press.

Muth, Kerstin. 2008. Die Wehrmacht in Griechenland - und ihre Kinder. Leipzig: Eurdora-Verlag.

Nunnally, Shayla C. 2012. Trust in Black America: Race, Discrimination, and Politics. New York: New York University Press.

Øland, Arne and Ingvill C. Mochmann. 2011. "Children of Danish Mothers and German Soldiers in Denmark 1938-48." In The Children of Foreign Soldiers, Vol. 2, edited by Lars Westerlund, 228-241. Helsinki: Nord Press.

Olsen, Kåre. 1998. Krigens barn: De norske krigsbarna og deres mødre. Oslo: Aschehoug.

Paxton, Pamela. 2007. "Association Memberships and Generalized Trust: A Multilevel Model across 31 Countries." Social Forces 86(1): 47-75.

Picaper, Jean-Paul and Ludwig Norz. 2004. Enfants maudits. Paris: Editions des Syrtes.

Pichler, Florian and Claire Wallace. 2007. "Patterns of Formal and Informal Social Capital in Europe." European Sociological Review 23(4): 423-435.

Popescu, Diana. 2014. "Fetele romance violate de soldatii rusi." Blogul Dianei, July 5. Available online at: http://www.diane.ro/2014/07/feteviolate-de-soldati-rusi.html.

Putnam, Robert. 1993. Making Democracy Work: Civic Traditions in Modern Italy. Princeton: Princeton University Press.

Rains, Olga, Lloyd Rains, and Melynda Jarratt. 2006. Voices of the Left Behind. Project Roots and the Canadian Children of World War II. Toronto: The Dundurn Group.

Riding, Alan. 1990. "Upheaval in the East: The Europeans; Fear on Germany Is Focus at East European Meeting." The New York Times, February 5. Available online at: http://www.nytimes.com/1990/02/05/world/ upheaval-east-europeans-fear-germany-focus-east-european-meeting .html (accessed June 14, 2014).

Rotenberg, Ken J., Nick Addis, Lucy R. Betts, Amanda Corrigan, Claire Fox, Zoe Hobson, Sarah Rennison, Mark Trueman, and Michael J. 
Boulton. 2010. "The relation between trust beliefs and loneliness during early childhood, middle childhood, and adulthood." Personality and Social Psychology Bulletin 36(8): 1086-1100.

Rothstein, Bo and Dietlind Stolle. 2003. "Social capital, impartiality and the welfare state: An institutional approach." In Generating social capital: Civil society and institutions in comparative perspective, edited by Marc Hooghe and Dietlind Stolle, 191-210. Houndmills: Palgrave Macmillan.

Seto, Donna. 2013. No Place for a War Baby. The Global Politics of Children born of Wartime Sexual Violence. Farnham and Burlington: Ashgate.

Smith, Helena. 2010. "Rape victims' babies pay the price of war." The Observer, April 16. Available online at: http://www.theguardian. com/world/2000/apr/16/balkans (accessed June 16, 2014).

Sønderskov, Kim Mannemar. 2011. “Does generalized social trust lead to associational membership? Unravelling a bowl of well-tossed spaghetti." European Sociological Review 27(4): 419-434.

Stelzl-Marx, Barbara. 2009. "Die unsichtbare Generation. Kinder sowjetischer Besatzungssoldaten in Österreich und Deutschland." Historical Social Research/Historische Sozialforschung 31(3): 352-372.

Stolle, Dietle and Marc Hooghe. 2004. "The Roots of Social Capital: Attitudinal and Network Mechanisms in the Relation between Youth and Adult Indicators of Social Capital." Acta Politica 39(4): 422-441.

Stout, Jay A. 2003. Fortress Ploesti: The Campaign to Destroy Hitler's Oil Supply. Havertown: Casemate.

Sztompka, Piotr. 1998. "Trust, Distrust and Two Paradoxes of Democracy." European Journal of Social Theory 1(1): 19-32.

Sztompka, Piotr. 1999. Trust. A Sociological Theory. Cambridge: Cambridge University Press.

Tait, Rosemary and Roxane Cohen Silver. 1989. "Coming to terms with major negative life events." In Unintended thought, edited by James S. Uleman and John A. Bargh, 351-382. New York: Guilford.

Uslaner, Eric. 2002. The Moral Foundations of Trust, New York: Cambridge University Press.

Uslaner, Eric. 2008. "Where you stand depends on where your grandparents sat: the inheritability of generalized trust." Public Opinion Quarterly 72(4): 725-740.

Viitanen, Tarja K. 2014. "The divorce revolution and generalized trust: Evidence from the United States 1973-2010." International Review of Law and Economics 38: 25-32.

Virgili, Fabrice. 2005. "Enfants de Boches: The War Children of France." In 
Children of World War II. The hidden enemy legacy, edited by Kjersti Ericsson and Eva Simonsen, 138-150. Oxford/New York: Berg.

Virgili, Fabrice. 2009. Naître ennemi. Les enfants de couples franco-allemands nés pendant la seconde guerre mondiale. Paris: Payot.

Voicu, Bogdan. 2010. Capital social în România începutului de Mileniu: Drumet in țara celor fără de prieteni? [Social Capital in Romania at the beginning of the Millennium: Traveller in the no-friends land?]. Iaşi: Lumen.

Voicu, Bogdan. 2014. "Immigrants and social trust: Mind the cultural gap?" Studia Politica XIV(2): 201-220.

Voicu, Mălina and Edurne Bartolomé-Peral. 2011. “Socialization or Context? Patterns of Support for democracy in Spain and Romania." Studia UBB Sociologia LVI (1): 95-113.

Weitsman, Patricia. 2007. "Children Born of War and the Politics of Identity." In Born of War. Protecting Children of Sexual Violence Survivors in Conflict Zones, edited by R. Charli Carpenter: 110-127. Bloomfield: Kumarian Press.

Wiegrefe, Klaus. 2010. "An Inside Look at the Reunification Negotiations." Der Spiegel, September 29. Available online at: http://www.spiegel. de/international/germany/germany-s-unlikely-diplomatic-triumphan-inside-look-at-the-reunification-negotiations-a-719848-druck.html (accessed June 15, 2014). 